\title{
A MOBILIZAÇÃO CULTURAL NA GESTÃO DE MUSEUS:A FORÇA DA PARTICIPAÇÃO COMUNITÁRIA E DA IDENTIDADE TERRITORIAL
}

Hilda Bárbara Maia Cezario' Eduardo Paes Barreto Davel ${ }^{2}$

\begin{abstract}
RESUMO
O propósito deste artigo é propor estratégias de gestão para iniciativas museológicas comunitárias tendo a cultura como eixo mobilizador.A Mobilização Cultural, portanto, consiste no desenvolvimento de uma cultura de valorização da participação e da identidade territorial, consideradas como forças essenciais destas iniciativas. Fruto de pesquisa qualitativa, análise documental e experiências de museus dentro e fora do Brasil, a pesquisa adota enfoque propositivo, buscando ser acessível e útil aos profissionais envolvidos com a prática de gestão dessas iniciativas: líderes comunitários, empreendedores socioculturais e gestores do setor público.
\end{abstract}

\section{PALAVRAS-CHAVE}

Gestão de museus comunitários; identidade territorial; participação comunitária; cultura; cultura organizacional.

\begin{abstract}
CULTURAL MOBILIZATION IN MUSEUM MANAGEMENT: THE POWER OF COMMUNITY PARTICIPATION AND TERRITORIAL IDENTITY
\end{abstract}

\begin{abstract}
The purpose of this article is to propose strategies of management for community museological initiatives, having the culture as mobilizing axis. Cultural Mobilization, thus, refers to the development of a culture of participation and territorial identity valorization, considered as essential forces for these initiatives. Emerging from qualitative research, documental analysis and experiences of museums in Brazil and abroad, the research is driven by a propositional approach, seeking to be accessible and useful to professionals enrolled with the managing practice of these initiatives: community leaders, sociocultural entrepreneurs and public managers.
\end{abstract}

\section{KEYWORDS}

Community museums management; territorial identity; community participation; culture; organizational culture.

' Graduada em Museologia pela Universidade Federal da Bahia.

2 Ph.D. em management pela École des Hautes études commerciales de Montréal, Canadá. Doutorado sanduíche na Graduate Faculty of Political and Social Science (New School for Social Research, New York). 


\section{Introdução}

Dentro das produções existentes sobre gestão de museus, pouco é produzido sobre as especificidades e necessidades dos museus comunitários, surgidos a partir da ideia de um museu socialmente engajado e promotor de transformações sociais. A lacuna é ainda maior quando se trata da ausência de práticas de gestão que levem em conta os fatores substantivos a essa tipologia de museu, tais como a participação comunitária e a identidade territorial. Referimo-nos às iniciativas museológicas que através da participação comunitária são capazes de manejar seus referenciais de memória, identidade e patrimônio em prol de ações coletivas transformadoras (LERSCH \& OCAMPO, 2004, 2009; PRIOSTI, 2010). Trata-se do museu compreendido como processo (VARINE- BOHAN, 20I4), vivo, que se cria e desenvolve através de um fazer participativo, acolhendo contínua e paulatinamente a diversidade cultural e identitária do seu meio. Consequentemente, estas iniciativas possuem uma relevância estratégica para construção de uma cultura cidadã, de sujeitos coletivos conscientes da própria história e memória, bem como, para a dinamização sociocultural de territórios, favorecendo a inserção de comunidades na economia criativa nas mais diversas escalas.

Entretanto, no campo da gestão de museus, o pouco que se encontra, refere-se, em sua maior parte, a manuais práticos (por exemplo, FOPP, I 997; GENOWAYS \& IRELAND, 2003; LORD \& LORD, 2005; MASON, 2004; BOYLAN, 2004; DAVIES, 200I) que tratam de forma pragmática o gerenciamento de espaços físicos, de acervos, equipes e recursos financeiros, a partir de uma perspectiva clássica dos processos, desconsiderando as variações decorrentes do contexto local, e menos ainda, a horizontalidade necessária em processos de gestão participativa. Ou seja, o uso destas ferramentas e conteúdos em museus comunitários não apenas se torna inadequado, mas perigoso, uma vez que, a padronização e a verticalidade próprias desses modelos de gestão, divergem, frontalmente, da natureza participativa e agregadora das múltiplas identidades territoriais, que envolvem um museu comunitário.

Neste artigo, partimos da premissa que a mobilização cultural garante o desenvolvimento de qualquer outra ação do museu comunitário. Essa mobilização, perpassa toda a sua dinâmica de atuação e sustenta as relações mais profundas. Nesse sentido, esta pesquisa destaca a necessidade da promoção de uma cultura própria para o desenvolvimento de um museu comunitário, enquanto organização substantivamente participativa e centrada na valorização da sua identidade territorial. Por outro lado, a pesquisa ressalta que é a prática desta nova cultura organizacional que potencializa as transformações socioculturais em um nível mais amplo, atuando num fluxo e contra fluxo na dinâmica cultural do território.

A vocação da pesquisa é propositiva, preocupando-se em ser acessível e útil aos profissionais envolvidos com a prática de gestão dessas iniciativas: líderes comunitários, empreendedores socioculturais e gestores do setor público. Por isso, o propósito da pesquisa é propor ações estratégicas e formas de operacionalização de diferentes práticas que corroboram para o desenvolvimento desta cultura. A metodologia de pesquisa é de tradição qualitativa, com base no estudo de casos múltiplos, sendo um de tipo holístico e três integrados (YIN, 2010). A coleta de dados orientou-se por documentos diversos (oriundos de museus e projetos sociais desenvolvidos com base na participação e/ou na identidade cultural), observação participante (realizada no caso holístico do Museu 
do Alto Sertão da Bahia' e em um dos casos integrados - Museu do Traje de São Brás de Alportel, Portugal2 ${ }^{2}$ ) e entrevistas semiestruturadas, que foram analisados e interpretados a partir da análise de conteúdo (COLBARI, 20I4).

\section{Cultura como Eixo da Mobilização}

Para compreendermos a mobilização cultural precisamos compreender o conceito de cultura e as relações existentes entre a cultura organizacional do museu e a cultura do território. Considera-se que "a cultura, em sentido largo, é todo o conjunto de obras humanas" (MELO, 20I3: 4I). Conjunto este, composto por conhecimentos, tradições, crenças, moral, leis, artes e todas as capacidades e costumes que estão num fluxo de contínua transmissão pelo ser humano, enquanto membro de uma sociedade, com vistas ao estabelecimento de um sistema de coesão social (MELO, 20I 3; SACHS, 2005). Essa transmissão, entretanto, não é pura e isenta dos significados e símbolos próprios de cada indivíduo, de maneira que uma seletividade acaba por perpassá-la, consciente ou inconscientemente, impactando as reproduções e alterações, aos poucos, do comportamento humano.Assim, a cultura, ainda que possa ser resultante de inúmeras experiências individuais, será sempre de caráter social, configurando-se num processo coletivo paradoxal, uma vez que é, concomitantemente, determinante em relação à instituição de padrões de comportamento para o desenvolvimento do ser humano e, por outro lado, determinada por este, preservando assim a contínua dinâmica da humanidade.

Para melhor compreender estes processos aplicados ao campo das organizações, adotamos o referencial de "dinâmica cultural" desenvolvido por Hatch (1993), apresentado na Figura $\mathrm{I}^{3}$ Este referencial facilita o entendimento da dinâmica necessária para o desenvolvimento de uma cultura de valorização da participação e da identidade territorial no seio de um museu comunitário. Por isso, o referencial pode ajudar na aplicação dos conceitos de cultura em estratégias de gestão que qualificamos de "mobilização cultural".

Nenhum dos elementos do referencial (entendimentos, valores, artefatos e símbolos) é um ponto de início ou fim do processo.A representação expressa a complexidade da dinâmica cultural, em que os processos categorizados existentes entre estes elementos (manifestação, realização, simbolização e interpretação) tornam-se mais significativos. $O$ processo, aparentemente cíclico, altera contínua e cotidianamente todos os elementos da dinâmica cultural. Entendimentos, valores, artefatos e símbolos estarão sempre em constante mudança. Nunca será possível retornar a um mesmo ponto, pois, ainda que tenhamos um mesmo artefato no decorrer do processo, sempre teremos diferentes entendimentos, valores e símbolos operando em uma cadeia de relações, por vezes, simultâneas.

Por exemplo, o "artefato" possui local de destaque no campo da museologia, abrigando nesta categoria as representações culturais do ser humano, de modo a torná- las tangíveis (ainda que possamos nos referir ao patrimônio material e imaterial). $O$ "artefato" é a materialização dos entendimentos, valores

\footnotetext{
'Museu de território, poli nucleado, com sede no município de Caetité e 10 núcleos pelo território, englobando também os municípios vizinhos de Guanambi e Igaporã. Fruto de uma iniciativa comunitária em 201 I, possui uma estrutura de gestão complexa que envolve a tutela jurídica do município de Caetité, a tutela técnica da Universidade do Estado da Bahia, Campi VI e XII, e a Associação de Amigos dos Museus (AMASB), responsável maior pela gestão dos seus recursos.

2 Localiza-se na vila de São Brás de Alportel, na região do Algarve, sul de Portugal. A mobilização

${ }^{3}$ Localiza-se na vila de São Brás de Alportel, na região do Algarve, sul de Portugal.A mobilização
} 
Figura I - Referencial da Dinâmica Cultural de Hatch ( 1993)

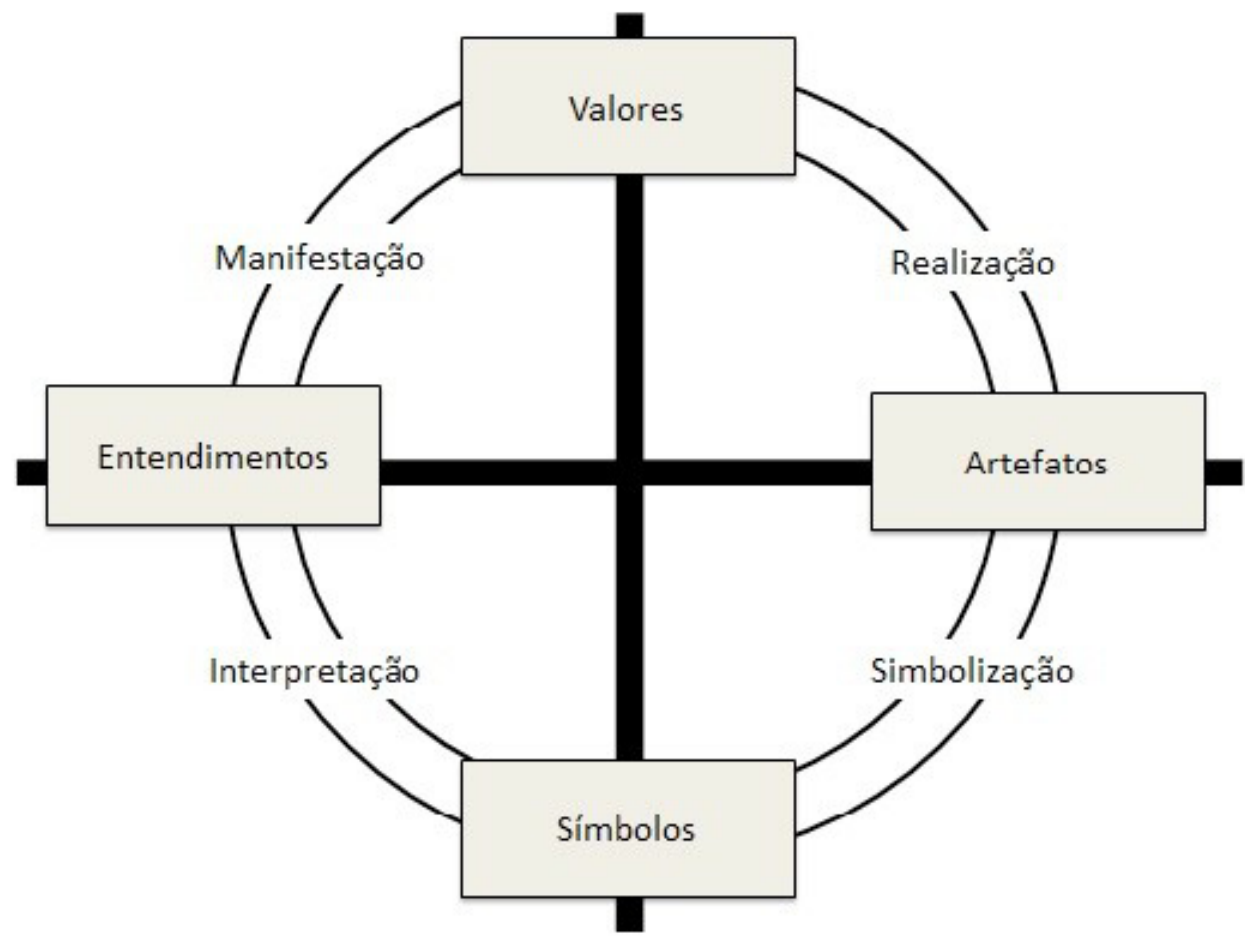

Fonte: Hatch (1993: 660).

e símbolos. Fruto do processo de "realização", ele é a expressão dos demais elementos da cadeia através de objetos, ações, manifestações, entre outros. Cada artefato, por sua vez, está suscetível ao processo de "simbolização" em que, cada indivíduo ou coletivo, estabelece com este, conexões para além do tangível, o imbuindo de significados e significantes diversos, num processo de comunicação em um nível mais profundo no campo do simbólico. Os "símbolos", muitas vezes, listados como artefatos, diferenciam-se destes na medida em que carregam uma significação para além da sua materialidade, que chamamos de valor simbólico. Um mesmo artefato pode carregar diversos significados a depender dos seus usos, contextos e valores empregados. Os símbolos são gerados e evidenciados durante todo o tempo, atuando diretamente na subjetividade humana, consciente ou inconscientemente. A partir deles ocorre o processo de "interpretação" e implementação de novos "entendimentos", que são as premissas e formulações cognitivas mais nucleares de cada indivíduo. Os "entendimentos" adotados para a formulação dos "valores" através do processo categorizado como "manifestação" revelam os princípios e padrões sociais de determinado meio. Os "valores" referem-se a estes códigos sociais compartilhados, que, por sua vez, são materializados em um processo de "realização", concretizando-se em novos "artefatos".

Girando no sentido contrário, a dinâmica também permanece, ainda que em perspectivas diferenciadas. A partir dos "artefatos", novos "valores" podem ser criados

ou os valores de base serão fortalecidos. A incorporação ou a evidência de um valor pode alterar num processo retroativo os entendimentos de origem. Assim, a lógica se aplica em toda a cadeia de relações entre os processos mencionados, oscilando entre a objetividade e a subjetividade, entre a estabilidade e a mudança, a atividade e a reflexividade, caracterizando a essência da dinâmica 
cultural, capaz de ser moldada e mobilizada em todas as suas vertentes.

Dentro desta dinâmica, a cultura é exercício social, à medida que se pode recorrer seletivamente aos repositórios passados de significados e de experiências históricas da sociedade, para moldar estratégias de ações (SWIDLER, I 986) e, assim, influenciar de forma mais ou menos consciente, os valores, os artefatos, os símbolos e os entendimentos integrantes de uma determinada sociedade. A cultura é um repertório, composto por símbolos, rituais e visões de mundo, que só adquiririam sentido pelo uso, quando mobilizados para orientar ações (ALONSO, 2009: 79). A cultura revela-se como um eixo de mobilização para a ação.

Dentre alguns estudos relacionados ao desenvolvimento da cultura organizacional (GEORGI et. al., 20I5; ALVESSON \& SVENINGSSON, 2008; RAVASI \& SCHULTZ, 2006; HATCH, 1993, 2000; HATCH \& SCHULT, 2008, 1997; GAGLIARDI, 1986), opta-se por compreender o lócus do museu comunitário a partir do modelo de Hatch (1993), indicando também o potencial de ação para os líderes destes equipamentos, ao compreenderem que podem agir estrategicamente sobre o modelo, inserindo novos artefatos e valores, provocando possíveis mudanças na cultura organizacional, inclusive de forma mais aprofundada, alterando o plano dos entendimentos e dos símbolos (HATCH, 2000). Em um museu comunitário, no entanto, esta dinâmica cultural organizacional deve ter por norte o seu compromisso social, assim como seus princípios básicos de atuação, diretamente ligado aos processos participativos e à valorização da diversidade identitária de um território.

Além disso, serão utilizadas também as lentes da cultura organizacional, sugeridas por Georgi et al. (2015, p.5-7), através de cinco perspectivas centrais - valores, histórias, enquadramentos, caixa de ferramentas e categorias. A cultura como valor se refere ao condicionamento da ação a partir das nossas preferências, tendo em vista o que nós prezamos e desejamos.A história refere-se à construção de narrativas com início, meio e fim, capazes de colaborar para a construção e transmissão de uma identidade e visão comum. A ideia de enquadramento trata da negociação coletiva para a definição de uma situação como central para, a partir desta, fazer uma leitura dos significados e ações, alinhando os códigos culturais existentes. $O$ repertório se refere à capacidade de combinar ou misturar componentes diversos (histórias, rituais, práticas, entre outros) para atribuir sentido a determinada situação ou tomar decisões, evidenciando como e "quanto" a cultura pode ser utilizada. Por fim, a cultura abarca as construções sociais que definem e estruturam os conceitos, possibilitando a distinção entre os objetos, pessoas e práticas, através da simplificação da carga cognitiva.

A partir dessas lentes, é possível perceber como a cultura pode ser mobilizada, de forma estratégica e prática, com potencial de mudança não apenas da cultura organizacional, mas de uma mudança cultural mais ampla no território. Qualquer processo de mudança deve levar em consideração que as alterações propostas devem ser compatíveis com o quadro de valores de base da organização para que se possa alcançar algum sucesso (GAGLIARDI, 1986), seja esta organização uma instituição, um coletivo ou uma comunidade maior. Além disso, a mudança cultural proveniente da ativação da cultura como eixo de mobilização, deve ser considerada num processo contínuo de construção cotidiana, através de uma ressignificação de códigos e de práticas (ALVESSON \& SVENINGSSON, 2008). Isso demonstra outro paradoxo que envolve o entendimento da construção cultural em um grupo que, de um lado, destaca o seu 
caráter processual e dinâmico e, de outro, a necessidade de relativa estabilidade de significados, símbolos e valores, para a própria coesão social (MELO, 20I3). Ainda que o entendimento de cultura esteja relacionado à ideia de movimento e mudança, a desconexão entre os elementos constitutivos da dinâmica cultural acarreta, por consequência, em uma crise cultural, com possíveis rupturas drásticas, desestabilizando a carga simbólica e, por conseguinte, as ações implicadas em toda esta dinâmica.

A gestão de um museu comunitário demanda, por vezes, uma mudança cultural organizacional em várias perspectivas, porém, destacam-se duas consideradas centrais e já enfatizadas anteriormente: a valorização da participação comunitária e a valorização da identidade territorial. Isto acarreta a introjeção destes aspectos como novos valores a serem cultivados de forma prática nesta organização, como um incremento cultural (GAGLIARDI, 1986), ou seja, ampliando, sem incompatibilidades, a sua cultura organizacional, que por essência já deveria considerar plenamente estes valores, mas que, na prática, por vezes, estão tão dissociados que colocam em risco a própria manutenção dessas iniciativas.

Sob esta ótica e à luz do modelo de Hatch (1993), podemos questionar se, em sua maioria, os artefatos, práticas e ações cotidianas do museu comunitários são coerentes com os seus valores e entendimentos. Existe interesse em se perceber claramente as possíveis relações entre a dinâmica organizacional no seio do museu, fruto das suas ações, e os reflexos sobre a comunidade na qual se insere? Esses questionamentos ressaltam que o processo de mudança é também processo pedagógico. $O$ intuito é provocar a mudança cultural dos envolvidos no museu de forma mais profunda, alcançando o nível de símbolos e entendimentos, provocando a transformação cultural que alimentará, de modo orgânico e sistêmico, o desenvolvimento de novos valores e práticas culturais, promovendo o desenvolvimento social de maneira mais ampla no território.

Para que um museu comunitário exista é necessário a mobilização cultural, em que a participação comunitária e a identidade territorial sejam "valores", a serem cultivados regularmente através de práticas, com significação simbólica forte e essencial para a sua contínua transmissão, chegando à construção de "entendimentos" consistentes que subsidiem estes valores no âmbito da coletividade. Essa mobilização deve ocupar o 'coração’ da iniciativa museológica comunitária. Do contrário, o que ocorre, com frequência, são inciativas que, não atentas a essa necessidade vital, são descontinuadas, enfraquecidas, diluídas em meio à dinâmica social imposta, tradicional, individualista e competitiva.

Para mobilizarmos esta cultura, faz-se necessário o uso da educação para a construção de uma cultura de desenvolvimento própria, de forma processual e dinâmica, evidenciando a dimensão cultural da iniciativa museológica com a base para a sustentabilidade própria e do território em que se situa. A cultura possui relação intrínseca com o desenvolvimento sustentável, sob pelo menos três perspectivas: (a) como um componente, agregando-se aos outros fatores social, econômico e ambiental;

(b) como mediadora do equilíbrio entre os três componentes já existentes para alcançar o desenvolvimento; e (c) como base estrutural que engloba todos os componentes, pois está na raiz de todas as decisões humanas (DESSEIN et al., 20I5). Partimos desta última perspectiva mais holística da relação entre cultura e desenvolvimento sustentável, apesar de, na prática, encontrarmos uma mescla destas três perspectivas. 


\section{Desenvolvendo uma Cultura de Participação Comunitária}

Nesta pesquisa, consideramos a participação comunitária em relação ao entendimento da participação cidadã, que consiste em poder cidadão, na medida em que há a sua redistribuição, permitindo aos cidadãos "o poder real para influenciar os resultados do processo" (ARNSTEIN, 2002: 2). Vincula-se, também, à ideia da participação popular que corresponde às formas de participação através de organizações coletivas mais autônomas e independentes do controle social do Estado, configurando-se, geralmente, como verdadeiros espaços de luta (GADOTTI, 20I4). Em síntese, a participação é um pressuposto básico da aprendizagem e da formação cidadã, base da educação libertadora (SANCHO-QUEROL, 2016). Sendo o museu comunitário fruto da vontade da comunidade e posto a serviço do seu desenvolvimento, a participação assume um papel indissociável à própria natureza desta tipologia de museu, devendo permear os quatro elementos da sua cultura organizacional (Figura 2).

\section{Figura 2 - Dinâmica Cultural da Participação}

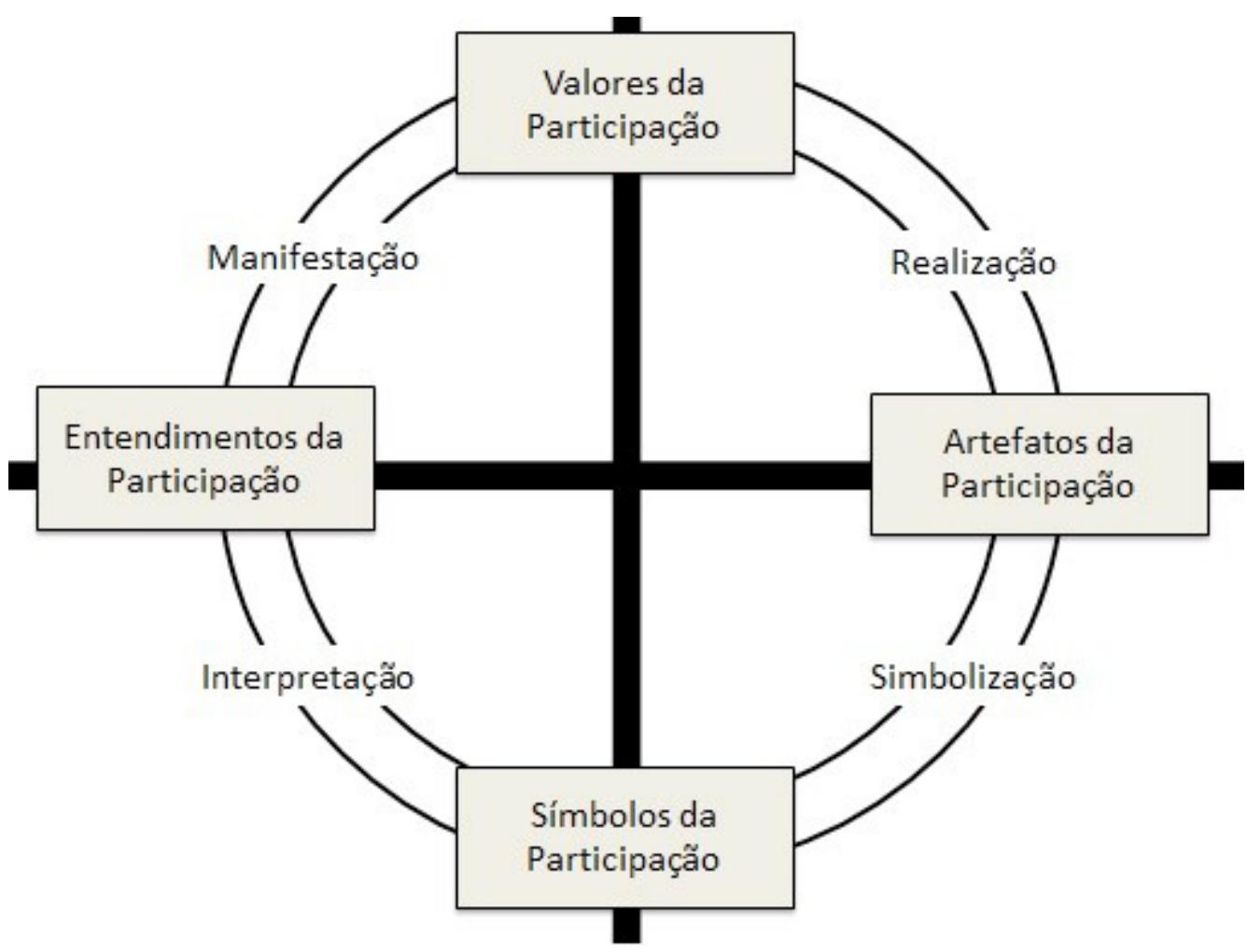

Fonte: Elaboração própria

A participação é um princípio substantivo, referindo-se a um processo ativo da comunidade, em que as pessoas participam das dinâmicas do museu, desde a concepção ao gerenciamento e desenvolvimento de suas atividades cotidianas (MOUTINHO, 2007; LERSCH \& OCAMPO, 2004, 2009; SANCHO-QUEROL, 2016). Trata-se de um 'entendimento de participação' que é base para a construção do 'valor de participação' que se insere no processo contínuo do 'fazer museu' e que, pelo caráter de exercício democrático e cultural cidadão, através da construção de 'artefatos' e 'símbolos de participação', coloca o museu como um potencializador de novos modelos de desenvolvimento, com base na descentralização e valorização dos recursos, sobretudo, locais (MOUTINHO, 
2007, 20 I0). O desenvolvimento acontece quando a população possui parte na tomada de decisões e tem consciência da importância da mobilização de todos os seus ativos no território, gerenciando os recursos locais e entendendo-se como parte deste (VARINE- BOHAN, 20I4). O museu é um empreendimento cooperado, que cresce de baixo para cima, em resposta às necessidades e anseios das pessoas que o compõem.

Entretanto, pregar a participação não garante que ela aconteça. É necessário traçar estratégias para que o museu crie condições concretas de participação, materializando os seus 'entendimentos' e 'valores de participação' através de práticas participativas. Isto é, os 'artefatos de participação' são fundamentais para que seus membros compreendam o significado desta cultura singular através de 'símbolos de participação' e compreendam-se como parte dela, acreditando na importância das suas contribuições para o todo, estabelecendo um grau de conexão organizacional e social por meio dos processos de 'simbolização' e 'interpretação'. Isso se torna essencial para a sustentabilidade do museu, assim como do próprio território no qual este se insere.

O exercício participativo é revelador de novas práticas potencialmente estratégicas para a finalidade proposta (BORDENAVE, 1983: 76). Veremos alguns exemplos de estratégicas que podem ser acionadas para dinamizar o desenvolvimento de uma cultura de participação comunitária.

\section{I Conhecendo e Aplicando Pedagogias Participativas}

Um estratégia relevante é capacitar os atores sociais locais para construirem espaços de participação no cotidiano do museu a partir do conhecimento e do uso de metodologias participativas. Estes espaços de participação podem ser considerados como artefatos e símbolos desta cultura que preza pela participação enquanto princípio e valor básico. Este conhecimento pode contribuir para a valorização da participação inserida de forma proposital na cultura organizacional do museu, prezando pelo estabelecimento da colaboração e da aprendizagem contínua (HURLEY et al., 1992 apud ALVESSON \& SVENINGSSON, 2008).

Muitas vezes, os espaços de participação, mal compreendidos, podem ocorrer de forma episódica e paralela, dando lugar a uma participação orientada, que pode chegar a seu mais baixo grau, que é o de simples informação (ARNSTEIN, 2002). Conhecer e aplicar pedagogias participativas contribui para o desenvolvimento de uma cultura através de uma prática social diferenciada, que carrega uma outra visão de mundo, em que as ações são ressignificadas, ganhando novos valores simbólicos, ao ponto que a disposição de uma sala em roda em um encontro poderá transmitir uma mensagem totalmente diferente.

Essa estratégia busca evitar que o princípio básico possa ser mascarado por uma infinidade de questões, intencionais ou não, por parte dos membros e dirigentes do coletivo do museu. Busca-se provocar os graus mais altos de participação que envolvam a tomada de decisões e uma distribuição equilibrada de poder gerencial. Nestes moldes, a participação deve ser valorizada, de modo a constituir-se no exercício de uma "metodologia permanente" da cultura organizacional e no modelo de gestão adotado (GADOTTI, 20I4:4).

$\mathrm{Na}$ prática, pode-se realizar uma ação formativa de capacitação da equipe, sobre os tipos, graus e níveis de participação (incluindo reflexão teórica com exemplos práticos) e metodologias participativas (e não convencionais), abordando diferentes metodologias participativas existentes. Em relação ao formato, 
sugere-se a realização de uma roda de conversa, tendo o profissional conhecedor de diferentes metodologias como mediador do diálogo. Importante envolver nesta atividade todas as pessoas que estarão no dia a dia operacionalizando as diversas ações do museu.Várias referências são disponíveis para fundamentar o tema da participação (ARNSTEIN, 2002; BORDENAVE, I983; CEZÁRIO et al., no prelo; NUNES, 2006) e das metodologias participativas e não convencionais (GIANELLA \& MOURA, 2009; MACHADO, 2016; MALDONADO, 2008).

A capacitação demanda o envolvimento de profissional específico que detenha conhecimento de diferentes metodologias e, preferencialmente, atuação em alguma em específico, de forma que a atividade formativa inclua uma parte teórico-metodológica e uma oficina prática, laboratório de uma ou mais metodologias. A partir da formação, espera-se que as ações possam ser desenvolvidas dentro do cotidiano do museu a partir do uso deste referencial, seja no desenvolvimento de um planejamento colaborativo, da construção de exposições compartilhadas, de inventários participativos, de construção coletiva da programação do museu, entre tantas. Enfim, o intuito é que a capacitação ofereça suporte para o desenvolvimento de práticas que contribuam para uma mudança cultural no próprio desenvolvimento das ações do museu, prezando pelos estímulos à participação.

A participação tem as suas ocasiões e "não quer dizer que todo o mundo deve participar de tudo, todo o tempo. Isto pode acarretar ineficiência e anarquia" (BORDENAVE, 1983: 80). Alguns cuidados, são necessários. Primeiro cuidado: não se deve convocar a participação em locais e horários inadequados, sem estrutura, sem preparação e sem organização (GADOTTI, 20I4). Sob a ideia falaciosa de participação, alguma liderança pode traçar estratégias de participação fadadas ao fracasso, seja de forma proposital por não querer de fato a participação, seja ignorando a atenção necessária para o desenvolvimento destes espaços. Apenas convocar um grupo à participação pode incorrer em reações opostas, se, por exemplo, o grupo interpretar que o horário e local em que foi chamado o encontro é incompatível com a realidade da maioria, desfavorecendo a participação, o que revela um processo de simbolização negativo da proposta da ação participativa. Se, equivocadamente, convocar o grupo a participar sem preparar o encontro, formas de compartilhar as situações para promover o espaço de diálogo e não apenas de informação e socialização de ideias, que não envolvem nenhum grau de poder em relação às decisões apresentadas.

Segundo cuidado: a participação comunitária não deve ser o equivalente a uma assembleia permanente, excluindo os mecanismos de representação. Essa atitude é extremamente prejudicial, pois não possibilita operacionalidade real às ações, sobretudo, quando tratamos de um coletivo com grande número de envolvidos. Deve ser o próprio grupo a "decidir, participativamente, quando tais ou quais membros devem participar ou não, em qual atividade, e quais assuntos devem ser objetos da consulta geral ou somente objeto da decisão por um grupo delegado" (BORDENAVE, 1983: 80). Esta forma potencializa o poder gerencial da assembleia. As mais simples definições passam a depender do aval de maioria reunida em assembleias. Neste tipo de ambiente, é comum aparecer a figura do 'coletivo ditador', em que alguns poucos membros mais expressivos e seguros em suas falas acabam sempre por ditar as regras do jogo assumindo uma representação simbólica do e no grupo, construída por suas posturas marcantes em repetição, que por vezes, ganham simbolicamente o título de líderes. Geralmente, esses sujeitos tem consciência do poder que exercem e, cientes disso, podem utilizar de forma prejudicial, manipulando o grupo e inibindo as 
particularidades de formas de expressão de outros indivíduos, bem como as proposições não tão efusivas, que acabam por não serem debatidas e passarem como se não fossem percebidas. Isto passa a se tornar, na verdade, um obstáculo à verdadeira participação pretendida, pois as pessoas não permanecem por muito tempo num ambiente em que não se sentem acolhidas, ouvidas e integrantes de fato. Lidar com esta questão possui relação tanto com as estratégias de gestão ligadas às potencialidades identitárias individuais, como também com as estratégias relacionadas ao papel do mediador.

Além disso, faz-se necessário o aprendizado de pedagogias participativas, que contribuam para a instrumentalização dos sujeitos frente aos desafios da iniciativa museológica comunitária, ressignificando os espaços de participação e atribuindo-lhes novos valores e sentidos, bem como contribuindo para o desenvolvimento dos cidadãos, a partir do uso de novas metodologias de ação, baseadas na participação. Também é preciso compreender o importante papel desempenhado pelo museu na formação cidadã a partir destas ações. Para além da participação no cotidiano do museu, existe o compromisso com a construção de uma sociedade democrática, participativa e solidária, que envolve o exercício da cidadania, e só assim, a transformação e o desenvolvimento social proposto é, de fato, alcançado.

\subsection{Compreendendo o Papel da Mediação e o Gerenciamento de Conflitos}

Outra estratégia relevante consiste em conhecer os diversos papéis assumidos pela mediação, interna ou externa ao grupo, para que a devida atenção seja dada a esta personagem dentro da iniciativa comunitária, uma vez que, o caminhar participativo do grupo muito dependerá da dinamicidade que a figura de mediação consegue imprimir nos espaços de participação. $O$ agente de mediação terá, obrigatoriamente, que lidar com as inúmeras variáveis da cultura organizacional, podendo ativar especificamente as "lentes” que julgar necessárias para a ação do grupo (GEORGI et al., 20I5). Dessa forma, caberá à mediação balizar os valores enunciados pelo grupo, conectar as histórias, fazer uso de enquadramentos para analisar conjuntamente as situações-problema e elencar as categorias provenientes do coletivo.

O primeiro passo é determinar se a mediação será assumida por alguém do próprio grupo, de modo natural ou previamente acordado, como é o caso de grupos que, a cada encontro, indicam uma pessoa para mediação, dando rotatividade a esse papel, o que é estratégico, pois estimula o desenvolvimento desta habilidade em diferentes sujeitos. A mediação interna pode ser tanto positiva, quanto negativa. Algumas vantagens podem ser observadas, a exemplo da possibilidade de prevenir situações de conflitos desnecessários, dado o conhecimento prévio que a pessoa mediadora terá de cada personalidade dentre os presentes, de forma a conduzir o diálogo por caminhos mais "seguros". Por outro lado, a desvantagem é que, geralmente, haverá essa mesma postura prévia dos demais integrantes em relação à mediação, ou seja, a depender do tipo de inserção desta pessoa no grupo, posturas excessivamente arredias ou o inverso, podem ocorrer, dependendo do grau de interlocução entre quem assume a mediação e os demais membros. O risco é deixar de focar no objeto da discussão e se ater à pessoa, veiculadora ou mediadora da proposta, o que é sempre um prejuízo para o grupo.

Quando a mediação é assumida por uma figura externa ao grupo, outros pontos surgem. Primeiro, pela falta de conhecimento prévio dos demais agentes 
do grupo, a mediação deverá concentrar-se ao máximo na percepção para além das palavras. Além disso, geralmente, terá de assumir uma postura mais "estimuladora" com o uso de perguntas, como: "e você, o que pensa sobre isso?", tanto para conhecer e dar a conhecer o pensamento de cada um e também do coletivo, como também para comunicar através desta pergunta o que realmente importa, a opinião do grupo (NUNES, 2006), fazendo uso de símbolos que, no contexto local, sejam associados ao espaço de construção coletiva. Isso é importante, pois na presença de uma mediação externa, o grupo pode se calar ou ficar mais omisso, sob a ótica de que 'quem vem de fora é maior detentor de saber'. Estas relações e esse local de poder assumido pela mediação são, portanto, delicados, uma vez que se corre o risco desta figura monopolizar falas e assumir um espaço de protagonismo, que não é o seu, em relação ao próprio grupo.

Seja interna ou externa, esses pontos são importantes para entender que o papel da mediação não pode ser exercido por qualquer pessoa, pois demanda habilidades específicas que nem todos estão preparados. Deve ser, portanto, uma função exercida de forma pedagógica, sobretudo se for desempenhado por alguém externo ao grupo, de maneira a preparar os agentes locais para assumir este espaço no processo do museu. Fica evidente que quem assume a mediação possui um compromisso maior que os demais integrantes do grupo, pois torna-se responsável por estimular constantemente a participação. A atividade de mediação baseia-se em duas competências: organizar a dinâmica do grupo e mediar conflitos (Quadro I). As duas competências requerem uma visão sistêmica do museu, considerando-o como processo com componentes múltiplos e interdependentes. Esta visão permite "desenvolver uma sensibilidade para captar a complexidade dos conflitos” (MALDONADO, 2008: 55).

Estratégias para a gestão criativa de conflitos são imprescindíveis para o desenvolvimento de processos participativos e colaborativos (MACHADO, 2016). As divergências devem ser trabalhadas e integradas numa reflexão que leve ao crescimento coletivo, através de ações como, por exemplo, rodas de escuta e de diálogo, em que a competência da mediação é fundamental. A mediação age neste transito tênue entre o individual e o coletivo dentro do grupo, exercitando a capacidade de identificação dos valores comuns, do compartilhamento de símbolos, para o fortalecimento de uma cultura organizacional que ofereça autonomia, ampliando o impacto no território decorrente desta mobilização cultural.

\section{Desenvolvendo uma Cultura de Valorização Identitária}

A ideia de identidade cultural remonta à origem do campo dos museus. Por muito tempo, a identidade foi compreendida como algo estático (uma substância, quintessência de valores e qualidades a priori positivas) e o museu como seu santuário (MENESES, 1993: 208). Em contraste, consideramos a identidade como 'prática social' (HOLLAND et al., 1998) e, assim como o museu, é também compreendida como processo (CANCLINI, 2003; CRAIB, 1998), constituída culturalmente e politicamente, levando em consideração sua relação territorial (SAQUET \& BRISKIEVICZ, 2009; DAVEL et al., 2016), através de múltiplos fragmentos (HALL, 2006). Compreendido como 'espaço socialmente construído' (LEFEBVRE, 2006; SANTOS, 2000), o território é fruto de uma interação dinâmica de fluxo e contra fluxo entre o material e o simbólico. Ao falar de identidade territorial, inclui-se o processo de negociação das múltiplas identidades em interação num determinado espaço, que possui delimitação física unicamente na dinâmica de construção/reconstrução estabelecida por estas relações. 


\section{Quadro I - Competências da Mediação}

\begin{tabular}{|c|c|}
\hline COMPETÊNCIA & HABILIDADES \\
\hline \multirow{2}{*}{$\begin{array}{l}\text { Organizar a } \\
\text { Dinâmica } \\
\text { Coletiva } \\
\text { (Nunes, 2006) }\end{array}$} & $\begin{array}{l}\text { Ter noção do tempo necessário para o aprendizado dos } \\
\text { sujeitos e do grupo. Ainda que a mediação tenha a visão sistê- } \\
\text { mica do museu, e consiga perceber os caminhos e etapas a serem } \\
\text { percorridos, faz-se necessário renunciar a certos encaminhamen- } \\
\text { tos que podem não espelhar o estado atual do processo de apren- } \\
\text { dizado da instância coletiva. }\end{array}$ \\
\hline & $\begin{array}{l}\text { Estar atento à dinâmica do grupo, como: controle de pauta, } \\
\text { inscrições e tempos de fala, retomada de todas as propostas levan- } \\
\text { tadas pelos membros, valorizando-as e garantindo uma reflexão do } \\
\text { grupo, conduzindo o processo sem hierarquias e ordens de priori- } \\
\text { dades adotadas aleatoriamente, prezando pela horizontalidade do } \\
\text { processo. }\end{array}$ \\
\hline \multirow{6}{*}{$\begin{array}{l}\text { Gerenciar } \\
\text { Conflitos } \\
\text { (Maldonado, } \\
\text { 2008) }\end{array}$} & $\begin{array}{l}\text { Conquistar a confiança do grupo. Com confiança, as pesso- } \\
\text { as colaboram mais e são menos reativas a posturas divergentes. } \\
\text { Entretanto, a mediação corre o risco de ser confundida com a } \\
\text { imagem de conselheiro, não apenas do coletivo, mas no campo } \\
\text { pessoal dos sujeitos envolvidos. Cabe à pessoa que assume este } \\
\text { papel identificar quando suas considerações tomam proporções } \\
\text { superiores ao entendimento coletivo e quando deve colocar limi- } \\
\text { tes naquilo que realmente lhe cabe. }\end{array}$ \\
\hline & $\begin{array}{l}\text { Comunicar de forma eficaz, construindo coletivamente as "re- } \\
\text { gras do jogo", explicando a dinâmica das propostas de trabalho e } \\
\text { o seu papel. Indica-se a expressão franca das pessoas em conflito, } \\
\text { através da escuta dos relatos sem interrupções, sem ofensas e hu- } \\
\text { milhações, pois estas posturas só fortalecem o conflito. }\end{array}$ \\
\hline & $\begin{array}{l}\text { Procurar ser neutra, evitando a tomada de partido em situa- } \\
\text { ções de conflito, distinguindo a sua própria visão da situação e a sua } \\
\text { função de mediação, que preza pelo controle emocional. }\end{array}$ \\
\hline & $\begin{array}{l}\text { Focar no desenvolvimento de alternativas para solucionar } \\
\text { a origem dos conflitos, retirando das discussões as cargas atri- } \\
\text { buídas a esta ou àquela pessoa. O conflito passa a ser compreendi- } \\
\text { do também como uma necessidade saudável do grupo, uma busca } \\
\text { por equilíbrios diante dos anseios das várias partes envolvidas no } \\
\text { museu. }\end{array}$ \\
\hline & $\begin{array}{l}\text { Ressaltar as competências do grupo para a solução, em de- } \\
\text { trimento do foco nas deficiências, que devem ser reconhecidas e } \\
\text { trabalhadas, porém nunca valorizadas. }\end{array}$ \\
\hline & $\begin{array}{l}\text { Promover a escuta ativa e o diálogo entre as diferentes } \\
\text { partes do conflito, buscando construir uma definição comum } \\
\text { para o problema, sobre o qual o grupo deve centrar forças em } \\
\text { busca de soluções. Trata-se da busca pelo consenso, um esforço } \\
\text { cooperado que consiste em encontrar uma solução aceitável para } \\
\text { todos. }\end{array}$ \\
\hline
\end{tabular}

Fonte: Elaboração própria. 
Desenvolver uma cultura de valorização identitária exige a construção e o compartilhamento de uma 'identidade territorial como valor' do grupo. Implica na provocação da reflexão sobre as instâncias mais profundas, os 'entendimentos de identidades' que ressoam sobre o território do museu, bem como, de cada envolvido no seu trabalho. Estes entendimentos em relação à identidade territorial, num processo de interpretação contínua, construído e reconstruindo laços, subsidiarão a manifestação dos valores identitários do grupo, expressando-se como semente para o crescimento da coletividade necessária ao processo de desenvolvimento do museu comunitário, materializando-se em seus espaços participativos referenciados pelas múltiplas identidades presentes, através de ações que podem ser consideradas na perspectiva de Hatch (1993) como os 'artefatos de identidade territorial'. Trata-se do desenvolvimento de uma cultura organizacional, derivada da gestão desta identidade territorial, como uma espinha dorsal transversal e permanente da iniciativa museológica comunitária, que vai unir, estruturar e motivar o grupo a partir de referências identitárias reconhecidas, simbolicamente como comuns e compartilhadas enquanto 'símbolos da identidade territorial', através dos seus processos participativos e da contínua simbolização presente nas ações desenvolvidas (Figura 3).

\section{Figura 3 - Dinâmica Cultural da Identidade Territorial}

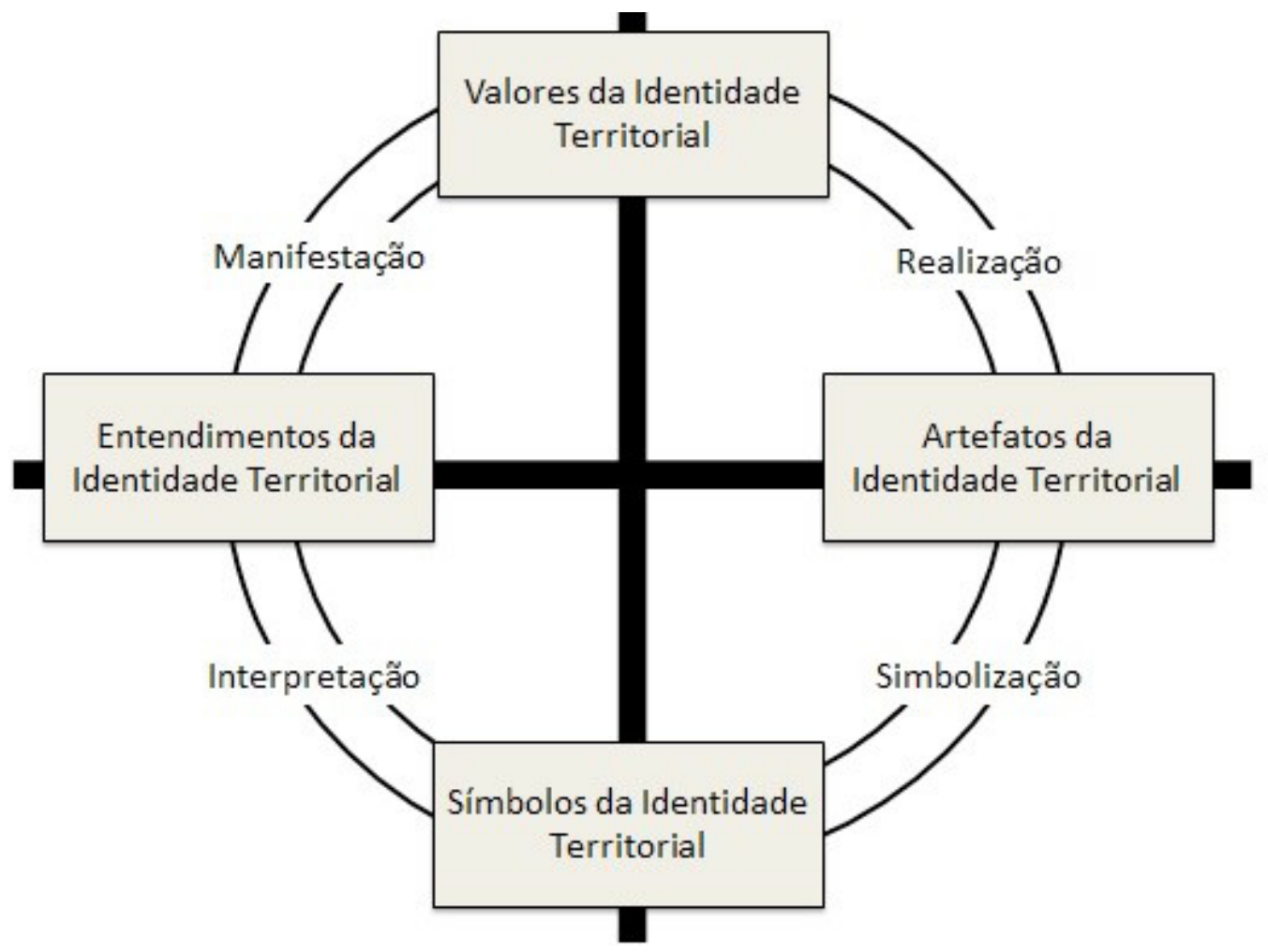

Fonte: Elaboração própria

A valorização da identidade é o principal ativo para um museu comunitário (LERSCH \& OCAMPO, 2004, 2009; SANTOS, 2008;VARINE, 20I 3). O museu comunitário representa um organismo vivo, acionando complexos processos de constituição do sujeito coletivo da comunidade, através da reflexão, do autoconhecimento, da criatividade, desencadeando processos de fortalecimento da identidade através da legitimação das histórias e valores das pessoas envolvidas, promovendo as comunidades como sujeitos coletivos que criam, recriam 
e decidem sobre sua realidade (LERSCH \& OCAMPO, 2004). Um dos aspectos da sustentabilidade do museu comunitário vincula-se à sustentabilidade da sua identidade territorial, definida como um processo, "uma constante negociação com aqueles ao nosso redor, a identidade é 'produto de concordâncias e discordâncias' e aberta a mudança” (CRAIB, 1998: 4).

O cultivo do associativismo local, recorrendo a ações com forte teor identitário, reverte-se em uma estratégia de mobilização cultural sustentável para o desenvolvimento do museu. Assim, o desenvolvimento da cultura de valorização identitária, em contraposição à participação, provém de um movimento mais exógeno ao museu em si e da mobilização dos ativos identitários de determinado território. Busca-se movimentar a sua cultura local para provocar uma mudança na cultura organizacional do museu, por meio da intervenção direta das possíveis múltiplas identidades existentes no cotidiano do museu. Entretanto, a dinâmica cultural não é unilateral e este movimento da cultura local para a organizacional, apesar de notável em dados momentos, se torna uma rede de fluxos e contra fluxos simultâneos.

\section{I Promovendo a Identidade Territorial como Força Motriz da Ação Coletiva}

Um exemplo de estratégia para desenvolver uma cultura de valorização identitária refere-se a uma ação permanente da iniciativa museológica comunitária: união de pessoas em um coletivo a partir das referências identitárias reconhecidas como comuns e compartilhadas através dos processos participativos já enunciados, também transversais e permanentes dentro do museu. Esta estratégia demanda o alinhamento dos 'entendimentos de identidade' para a construção dos valores, artefatos e símbolos comuns ao coletivo.

Pode-se dizer que uma iniciativa museológica comunitária nasce da promoção coletiva de uma identidade territorial. Entretanto, como podemos promover a identidade territorial? Através de ações que provoquem reflexões sobre a identidade, instigando as múltiplas visões do grupo sobre sua história, referenciais de memória e patrimônio, bem como, sobre os referencias de espaços físicos, seja histórico, arquitetônico ou natural, e ainda, sobre sua teia de relações sociais locais, seja de hierarquia, poder, política. $O$ estímulo a essa reflexão partirá, geralmente, dos 'artefatos de identidade' evidenciados pelo grupo.

Esse emaranhando enunciará um conjunto de elementos culturais (por exemplo, visão de mundo, valores, símbolos, artefatos e narrativas) que fornecerá substância para a construção de uma identidade territorial. $O$ indivíduo, geralmente, só se torna um parceiro e colaborador/construtor do museu, quando se identifica ou se sente integrado pela identidade territorial que apreende, ou seja, quando percebe que há nesta interação um compartilhamento de valores, entendimentos e histórias comuns, podendo assim, vir a ser mais um agente comunitário a compor o grupo em favor da construção do museu, agregando a este também a sua visão enquanto indivíduo para a construção de uma identidade que leve em conta os componentes do território, em sua diversidade de visões históricas e fatores sociais, linguísticos, econômicos, paisagísticos, culturais e políticos.

Mesmo quando falamos de identidade, necessitaremos das estratégias participativas, para que as pessoas se sintam integrantes e ainda que não se identifiquem de imediato, percebam o espaço propício à participação e aberto para acolher novas visões que colaborem para a construção/reconstrução, na 
contínua interpretação dos símbolos da identidade e no desenvolvimento de novos entendimentos sobre o território.Podendo assumir formatos diversos, tais como rodas de conversas, exposições socioeducativas, apresentações da proposta do museu em encontros e eventos, participação em rádios e outros meios de comunicação, oficinas, entre outras, estas ações devem promover a reflexão sobre o elo comum que une todos os envolvidos em um processo de contínua identificação. Essa identificação e compartilhamento podem ser percebidos de diversas formas, inclusive de modo concomitante, seja a partir do reconhecimento de uma identidade tida como emergente do grupo, seja através do processo de construção de uma identidade territorial de forma intencional pelos atores sociais envolvidos, destacando-se também como um processo de afirmação política do próprio grupo (MOURÃO \& CAVALCANTE, 2006; SAQUET \& BRISKIE$\mathrm{VICZ,} \mathrm{2009).} \mathrm{Tanto} \mathrm{em} \mathrm{um} \mathrm{como} \mathrm{no} \mathrm{outro,} \mathrm{o} \mathrm{posicionamento} \mathrm{do} \mathrm{grupo} \mathrm{a} \mathrm{partir}$ da identidade cultural é sempre uma ação política, que implicará na postura seja do grupo ou do indivíduo perante a realidade que o cerca, construindo, portanto, uma identidade territorializada pelos atores envolvidos no processo. $A$ associação de atores sociais diversos a partir de um elo identitário, relaciona-se como a mesma lógica da formação de redes (MARTINHO, 200 I).

Perguntas norteadoras podem auxiliar o grupo a construir os limites da sua identidade enquanto iniciativa museológica, do mesmo modo que podem apresentar a diversidade deste grupo.Alguns exemplos: $O$ que representa a sua cultura? Com o que se identifica e quais são as representações importantes dessa identidade? $O$ que você considera importante preservar como registro da sua memória e da sua identidade? O que você gostaria de apresentar em um museu que representasse a sua cultura? A categorização destas respostas indicará os 'entendimentos de identidade' de cada ponto de vista, bem como a possibilidade de alinhamento em torno de 'valores e símbolos de identidade' comuns, permitindo a emergência de uma identidade territorial aliada ao senso de coletividade do grupo em prol do museu.

\subsection{Reconhecendo as Matrizes Identitárias do Território do Museu}

Outra estratégia importante é a realização de ações que promovam a reflexão sobre as matrizes identitárias do território. A reflexão sobre a pluralidade de conhecimentos, tradições e crenças presentes no território de um museu comunitário é fundamental. Essa reflexão, de modo mais aprofundado, consiste num grande desafio enfrentado por qualquer museu e contribui para a abertura de um novo olhar sobre os processos de construção e reconstrução das múltiplas identidades contemporâneas presentes num mesmo território, que devem ser levadas em consideração, tendo em vista a diversidade cultural para um movimento real em prol do desenvolvimento local.

São ações podem assumir formatos diversos, a depender da comunidade. Se inserem na dinâmica cultural por meio de novos 'artefatos de identidade', com ações simbólicas que expressem os 'valores identitários' construídos pelo grupo. Duas atividades básicas ajudar a lidar com este desafio: (a) encontros de capacitação a partir de facilitadores mapeados dentro e fora da comunidade sobre o processo de constituição sócio-histórica daquele território, buscando identificar e compreender a pluralidade presente, com vista a integração de um grupo diverso capaz de dialogar em prol de um objetivo comum, ainda que hajam interesses variados; e, (b) ações de intercâmbio e troca de saberes entre grupos étnicos e culturais diferenciados presentes no território, com vistas a 
ampliação do conhecimento geral e redução de tensões e conflitos. Ao expor a multiplicidade das expressões identitárias do território, o grupo gestor contribuirá para um alinhamento amplo do museu, respeitando e valorizando a diversidade cultural local.

Essas ações devem ser realizadas à luz de uma "ecologia de saberes" (SANTOS, 2007), na qual se entende que "não há conhecimento que não seja conhecido por alguém e para alguns objetivos. Todos os conhecimentos sustentam práticas e constituem sujeitos" (SANTOS, 2007: 27). Dessa forma, respeita-se as relações entre o conhecimento científico e o não científico, alargando o campo para a compreensão das subjetividades que entremeiam um território. Isso pode facilitar o trabalho com o patrimônio, a identidade e a memória social que, por natureza, trata-se de campos assumidamente polissêmicos, e na maior parte das vezes, permeados por conflitos. Quanto maior a interação e o diálogo entre as várias vozes presentes no território, numa lógica de construção permanente de significados para estes termos, maior a probabilidade de encontrar as contradições e de delinear uma identidade territorial que englobe a multiplicidade cultural encontrada e, em consequência, maior o potencial para um desenvolvimento social local consistente.

\subsection{Potencializando as Expressões Identitárias Individuais}

Outra estratégia consiste na identificação da variedade dos anseios e potenciais identitários que compõem a coletividade do museu. Reunidos em torno de um elo identitário norteador em prol de uma causa comum, haverá sempre uma diversidade de agentes formando um mesmo coletivo, carregados de valores, histórias, visões de mundo e diversos códigos culturais, que nem sempre estão reunidos num conjunto de significados coletivos maior. Cada indivíduo carrega para o grupo a sua própria carga identitária, que consiste na identificação de quem ele é, o que faz, quais os seus sonhos, seus anseios, sua visão de mundo, seus gostos e desgostos, etc. Ao unir-se e dar vida a uma organização coletiva, os sujeitos não se anulam, nem anulam seus interesses individuais, ainda que neste espaço compartilhado adotem o interesse coletivo como prioritário. Logo, identificar essas múltiplas identidades que compõem o museu, agora não no intuito de delinear uma identidade territorial representativa, mas sim, no intuito de visualizar o potencial de cada indivíduo em prol do grupo e do grupo para cada indivíduo.

Além disso, cada indivíduo carrega também seus anseios próprios, suas expressões, seus gostos e interesses. Compreender que é a base identitária múltipla e integradora de anseios diversos que direciona o propósito de existência do museu é fundamental, pois este conhecimento torna-se um potencial para o desenvolvimento de frentes de trabalho e de valorização e integração contínua também dos indivíduos participantes.A partir da compreensão do denominador comum que sustenta a identidade e cultura organizacional do museu, torna-se importante a compreensão dos anseios diversos, comuns entre alguns, mas não compartilhado por todos, levando-se em conta, assim, não só a identidade coletiva, mas também a identidade de cada indivíduo como um potencial fruto da ativação das múltiplas identidades culturais locais. São os pequenos nós que entremeiam o grupo e que revelam possibilidades identitárias diferenciadas que, se forem bem compreendidas, podem se tornar estruturais para o desenvolvimento do museu num território cada vez mais amplo, chegando a constituir, uma simbiose entre os ativos da cultura local e da cultura organizacional deste equipamento. 


\section{Discussão e Repercussões}

Iniciativas museológicas comunitárias tem se multiplicado pelo Brasil afora, ao mesmo tempo que crescem os questionamentos sobre o teor e o propósito destas inciativas. Enquanto as reflexões teóricas apontam para museus ideais, na prática, a grande maioria dos espaços museológicos encontra-se no limbo. As críticas surgem, indicando o assistencialismo museológico que prepara o museu para ser consumido pela comunidade e não ela como criadora e gestora da sua própria dinâmica.

Neste artigo, procuramos fornecer pistas para modificar essa situação crítica, formulando um conhecimento aplicado e acessível, postulando que para assegurar uma gestão coerente de uma iniciativa museológica comunitária, é primordial entender a dinâmica cultural que rege essa organização. Ao mesmo tempo, a linha é tênue entre o processo dinâmico e o nível de estabilidade que dá coesão ao grupo. Mesmo numa perspectiva que entende a organização como processo, algum nível de ordem e controle é necessário para não recair num caos (WATSON, 2005).

O compromisso das lideranças envolvidas com a criação de condições concretas de participação é fundamental. Falamos, portanto, de um movimento que favorece a descentralização e redistribuição de poderes, da autonomia do museu e dos sujeitos, contribuindo para a emancipação destes a partir do desenvolvimento de uma cultura cidadã endógena ao próprio museu. Por outro lado, pensar a gestão com base na identidade territorial, é provocar interfaces, sinergias entre a base identitária que dá vida a uma iniciativa museológica comunitária ao manancial de múltiplas identidades presentes em seu território.

Mobilizar cultural significa comprometer-se com o desenvolvimento de uma cultura de participação e de valorização identitária, que não atinge apenas o âmbito organizacional do museu, mas que possibilita a este, pelo menos, três níveis diferenciados de transformação social. $O$ primeiro nível refere-se às ações voltadas para o desenvolvimento local com vistas à promoção de territórios sustentáveis dentro de um modelo de desenvolvimento integrado, equitativo e solidário, que está atento às dimensões sociais, ambientais e econômicas, adotando a cultura como mobilizadora de todas elas (por exemplo, a melhoria de condições de vida, a possibilidade de acesso a recursos e educação, possibilidades de desenvolvimento econômico a partir do patrimônio local). $O$ segundo nível diz respeito ao desenvolvimento de uma cultura organizacional com novas práticas de gestão, totalmente avessas às práticas tradicionais, envolvendo diretamente a valorização de espaços de participação e a valorização identitária. Este é o principal campo de atuação da mobilização cultural proposta, apesar de entender que ela extrapola os limites organizacionais. $O$ terceiro nível é o mais profundo de transformação do indivíduo, ao exercitar a construção participativa e perceber sua identidade valorizada, seja atuando na gestão do museu, seja participando das ações promovidas por este. Neste nível, desenvolvem-se os cidadãos, contribuindo para a emancipação dos sujeitos.

\section{Conclusão}

A mobilização cultural é o coração que pulsa vitalidade para todas as ações de uma iniciativa museológica comunitária, de forma que, em suas práticas, a essência desta mobilização deve ser perceptível. Esta mobilização permite a abertura de novos e contínuos espaços de participação social no dia a dia do 
museu, assim como na compreensão de que haverá realidades com diferentes gradações de participação por parte de cada pessoa envolvida.

Em prol da mobilização cultural, as estratégias de gestão relacionadas à valorização da participação e à valorização identitária percorrem caminhos distintos que, por vezes, se entrelaçam. Enquanto as estratégias que visam o conhecimento de pedagogias participativas e a compreensão do papel da mediação estão focadas no desenvolvimento de uma cultura organizacional própria que alimente transformações socioculturais mais amplas, as estratégias de valorização identitária, por sua vez, partem da mobilização dos ativos culturais identitários do território como um todo para a construção de uma identidade e cultura organizacional mais adequada e fortalecida destes museus.

A mobilização cultural é trabalho permanente na interação entre a cultura organizacional e a cultura territorial, atuando diretamente no fluxo da dinâmica cultural, possibilitando intervenções sistematizadas e conscientes em seus processos, desde a inserção ou alteração dos 'artefatos' às mudanças mais profundas, perpassando o campo mais denso do simbólico das relações humanas, permitindo a construção de 'símbolos' e 'entendimentos' mais adequados aos valores pretendidos para o pleno desenvolvimento do museu, e consequentemente, do território.

\section{Referências}

ALONSO, A. As teorias dos movimentos sociais: um balanço do debate. Lua Nova.Vol. 76, p. 49-86, 2009.

ALVESSON, M; SVENINGSSON, S. Changing Organizational Culture: Cultural change work in progress. New York: Routledge, 2008.

ARNSTEIN, S. R. Uma escada da participação cidadã. Revista da Associação Brasileira para o Fortalecimento da Participação - PARTICIPE, v. 2, n. 2, p. I-I 7, 2002.

BAUMAN, Z. Ensaios sobre o conceito de cultura. Rio de Janeiro: Zahar, 2012. BOYLAN, P. (org.). Como gerir um museu: Manual Prático. Paris: ICOM, 2004. BORDENAVE, J. O que é Participação? São Paulo: Editora Brasiliense, 1983.

CANCLINI, N. G. Culturas Híbridas: estratégias para entrar e sair da modernidade. São Paulo: Eadusp, 2003.

CÂNDIDO, M. M. D. Gestão de Museus, um desafio contemporâneo: diagnóstico museológico e planejamento. Porto Alegre: Medianiz, 2013.

CHAGAS, Mário de S. Um novo (velho) conceito de museu. Cadernos de Estudos Sociais, vol.I, n.2, p. I83-192, 1985.

CHAGAS, Mario; GOUVEIA, Inês. Museologia Social: reflexões e práticas. Cadernos do CEOM,Ano 27, n. 4I, p. 9-22, 2014.

COLBARI,A.A análise de conteúdo e a pesquisa empírica qualitativa. In: Moulin de Souza, E. (Ed.). Metodologias e analíticas qualitativas em pesquisa organizacional. Vitória: EDUFES, 2014. 24I- 272.

CRAIB, I. Experiencing Identity. London: Sage Publications, 1998.

DAVEL, E.; VERGARA, S. C.. Desafios relacionais nas práticas de gestão e de organização. RAE-Revista de Administração de Empresas, vol. 45, n. I, p. I0-I 3, 2005

DAVEL, E.; SANTOS, F.; DANTAS, M. Identidade Cultural de Territórios como Política de Gestão.Anais do Anais do XL ENANPAD - Encontro da Associação Nacional de Pós-Graduação e Pesquisa em Administração. Sauípe, Bahia, 2016.

DAVIES, S. Plano Diretor. São Paulo: Editora da Universidade de São Paulo; Fun- 
dação Vitae, 200I.

DAVIS, Peter. Ecomuseums: a sense of place. London: Leicester Museum Studies, 1999.

DAVIS, Peter. Places, "Cultural Touchstones" and the concecpt of the ecomuseum. In: II Encontro Internacional de Ecomuseus. Rio de Janeiro:Tacnet Cultural Ltda, 200I.

DESSEIN, J.; SOINI, K.; FAIRCLOUGH, G; HORLINGS, L. (eds) Culture in, for and as Sustainable Development. Conclusions from the COST Action ISI007 Investigating Cultural Sustainability. University of Jyväskylä, Finland, 2015.

DIEGUES,A. C. S. Desenvolvimento sustentável ou sociedades sustentáveis - da crítica dos modelos aos novos paradigmas. São Paulo em Perspectiva, Vol.6 , n. I/2, p.22-9, 1992.

FOPP, M.A. Managing Museums and Galleries. London: Routledge, I 997. FREIRE, Paulo. Pedagogia do Oprimido. Rio de Janeiro: Paz e Terra, 1987.

FREIRE, Paulo. Pedagogia da indignação: cartas pedagógicas e outros. São Paulo: Editora UNESP, 2000.

GADOTTI, M. Gestão Democrática da Educação com Participação Popular no Planejamento e na Organização da Educação Nacional. Conferência Nacional de Educação 20|4. Brasília: FNE, $20 \mid 4$.

GAGLIARDI, P.The Creation and Change of Organizational Cultures:A Conceptual Framework. Organization Studies.Vol. 7, n.2, p. I I7-I34, 1986.

GENOWAYS, H. H.; IRELAND, L. M. Museum Administration: an introduction. Walnut Creek:AltaMira Press, 2003.

GEORGI, S.; LOCKWOOD, C.; GLYNN, M. The Many Faces of Culture: Making Sense of 30 Years of Research on Culture in Organization Studies, The Academy of Management Annals, v. 9, n. I, p.I-54, 2015.

GIANELLA,V.; MOURA, M. S.. Gestão em rede e metodologias não convencionais para a gestão social. Salvador: Editora CIAGS, 2009.

HALL, S. Identidade Cultural na Pós-Modernidade. Rio de Janeiro: DP\&A Editora, 2006.

HATCH, M.J.The Dynamics of Organizational Culture. The Academy of Management Review, v. 18, n. 4, p. 657-693, 1993.

HATCH, M. J. The cultural dynamics of organizing and change. In:ASHKANASY, N. M.;WILDEROM, C. P. M.; PETERSON, M. F. (ed). Handbook of organizational culture and climate. Thousand Oaks: Sage Publications, 2000.

HATCH, M. J.; SCHULTZ, M. Relations between organizational culture, identity and image. European Journal of Marketing, v. 3 I, n. 5/6, p. 356-365, 1997.

HOLLAND, D.; LACHICOTTE,W.J.; SKINNER, D.; CAIN, C. Identity and Agency in Cultural Words. Cambridge: Harvard University Press, 1998.

JANEIRINHO, Raquel. Património, museologia e participação: Estratégias Museológicas Participativas no Concelho de Peniche. 20I2, I42 f. Dissertação (Mestrado em Museologia) - Departamento de Museologia, Universidade Lusófona de Humanidades e Tecnologias, Lisboa.

LEFEBVRE, H. La production de l'espace. Paris: Éditions Anthropos, 2000.

LERSCH, T. M.; OCAMPO, C. C. O conceito de museu comunitário: história vivida ou memória para transformar a história? In: Conferencia Nacional de la Asociación Nacional de Artes y Cultura Latinas, Kansas City, Missouri, 2004. 
LERSCH,T.M.; OCAMPO, C. C. Manual para la creación y desarrollo de museos comunitarios. Fundación Interamericana de Cultura y Desarrollo (ICDF). Bolivia: Artes Graficas Sagitario, 2009.

LORD, B.; LORD, G. D. Manual de gestión de museos. Barcelona:Ariel, 2005.

MACHADO,V. Diálogo e Gestão Criativa de Conflitos: um método centrado na complexidade do pensamento e simplicidade da ação. Lauro de Freitas: Editora Solisluna, 2016.

MALDONADO, M.T. O Bom Conflito: juntos buscaremos a solução. São Paulo: Integrare Editora, 2008.

MASON, T. Gestão Museológica: Desafios e Práticas. São Paulo: Editora da Universidade de São Paulo, 2004.

MARTINHO, C. Algumas palavras sobre rede. In: SILVEIRA, C. M. S.; REIS, L. C. (orgs). Desenvolvimento local: dinâmicas e estratégias. Rio de Janeiro: Rede DLIS, 200 I, p. 24-30.

MELO, Luiz Gonzaga de. Antropologia Cultural: iniciação, teoria e temas. Petrópolis:Vozes, 2013.

MENESES, U., T. Bezerra de. A problemática da identidade cultural nos museus: de objetivo (de ação) a objeto (de conhecimento). Anais do Museu Paulista, vol. I, n. I, p. 207-222, I 993.

MOURÃO, A. R., CAVALCANTE, S. O processo de construção do lugar e da identidade dos moradores de uma cidade reinventada. Estudos de Psicologia, Vol.I I, n.2, p. I43-I5I, 2006.

MOUTINHO, M. (Coord.) Sobre o Conceito de Museologia Social. Cadernos de Sociomuseologia, vol. I, n. I, p.7-9, 1993.

MOUTINHO, M. C. The informal Museology. Cadernos de Sociomuseologia, vol.27, p. 183-188, 2007.

MOUTINHO, M. Definição Evolutiva de Sociomuseologia: proposta de reflexão. Cadernos do CEOM, Ano 27, n. 4I, p. 423-427, 2014.

NUNES, D. Pedagogia da Participação: trabalhando com comunidades. Salvador: UNESCO/Quarteto, 2006.

PRIOSTI, O. M. Memória, comunidade e hibridação: Museologia da Libertação e estratégias de resistência. (Doutorado em Memória Social) - Centro de Ciências Humanas e Sociais, Universidade Federal do Estado do Rio de Janeiro, 2010. PRIOSTI, O. M.; MATTOS, Y. Caminhos e percursos da museologia comunitária. Cadernos de Sociomuseologia, v. 28, p. I-16, 2007.

RATTNER, Henrique. Sustentabilidade - uma visão humanista. Ambiente \& Sociedade, Ano II, n. 5, p.233-40, 1999.

SANCHO-QUEROL, L. El Patrimonio Cultural Inmaterial y la Sociomuseología: um estudio sobre inventarios. Cadernos Sociomuseologia, $n^{\circ}$ I. Lisboa: ULHT, 2016.

SANTOS, Boaventura de Sousa. Para além do pensamento abissal: das linhas globais a uma ecologia de saberes. Novos estudos CEBRAP, n. 79, p. 7I-94, 2007. SANTOS, M. C.T. M. Encontros Museológicos: reflexões sobre a museologia, a educação e o museu. Rio de Janeiro: Minc/IPHAN/DEMU, 2008.

SAQUET, M., BRISKIEVICZ, M.. Territorialidade e identidade: um patrimônio no desenvolvimento territorial. Caderno Prudentino de Geografia, vol. I, n. 3 I, p.3- 
I6, 2009.

SCHEINER, T. C. M; BRULON SOARES, B. C.A ascensão dos museus comunitários e os patrimônios comuns: um ensaio sobre a casa. In: $X$ Encontro Nacional da Associação Nacional de Pesquisa em Ciência da Informação, João Pessoa, João Pessoa: Idéia, 2009.

SCHEINER, Tereza Cristina. Repensando o museu integral: do conceito às práticas. Boletim Museu Paraense Emílio Goeldi. Ciências humanas, vol. 7, n. I, p. I5- 30, 2012.

SWIDLER, A. Culture in Action: Symbols and Strategies. American Sociological Review, v. 5I, n. 2, p. 273-286, 1986.

VARINE-BOHAN, Hugues de. As Raízes do Futuro: o patrimônio a serviço do desenvolvimento local. Porto Alegre: Medianiz, 2012.

VARINE-BOHAN, H. O museu comunitário como processo continuado. Cadernos do CEOM, Ano 27, n. 4I, p. 25-35, 2014.

YIN, R. K. Estudo de caso: planejamento e métodos. Porto Alegre: Bookman, 2010.

ZANETTINI ARQUEOLOGIA. Plano Museológico do MASB. Volume II. São Paulo: Zanettini Arqueologia, 2013.

Artigo recebido em fevereiro de 201 7. Aprovado em julho de 2017. 